\title{
Re-writing the "rules of engagement": Using critical reflection to examine ableist social work practice
}

\author{
Jessica Fox, Queensland University of Technology, Australia
}

\begin{abstract}
INTRODUCTION: Normative beliefs and practices reaffirm a hegemonic construction of human ability that legitimises the socio-cultural status quo. This disenfranchises people with diverse abilities who are excluded from this construction whilst simultaneously normalising the structural inequality and oppression that they experience. Helping professions such as social work often provide support to people who are disadvantaged by these social structures. However, practitioners within these fields are not immune to the influence of socio-cultural norms, therefore it is essential for them to reflect on the ways in which they might reproduce them within their practice.
\end{abstract}

APPROACH: This article outlines my experience of using critical reflection as a research methodology to examine an incident from my practice. Deconstruction and reconstruction methods were used to analyse the normative assumptions within my construction of this incident.

REFLECTIONS: The deconstruction analysis revealed how assumptions about impairment within my account of the incident were underpinned by ableist discourses. Reconstructing this through a neurodiversity lens enabled me to generate new insights around the anti-oppressive potential for using a pluralistic approach that undermines hegemonic constructions of ability.

CONCLUSIONS: By critically reflecting on this incident, I realised the importance of challenging normative assumptions when practising within neoliberal contexts where socio-cultural hegemony is amplified.

KEYWORDS: Critical reflection; social work; ableism; neurodiversity

AOTEAROA

NEW ZEALAND SOCIAL WORK 33(1), 44-54.

CORRESPONDENCE TO: Jessica Fox

Jessicafox30@outlook.com
Ableism involves devaluing the ways of being and doing that deviate from what is considered normative or functional according to the socio-cultural status quo (Oliver, 2013). This is perpetuated at the macro (structural) level through systems that disadvantage those with diverse abilities, and at the micro (interpersonal) level through attitudes and practices that de-value certain social identities (Burgers \& Beukeboom, 2016). Despite the importance that is placed on the interpersonal dimensions of social work practice, there is currently a limited analysis of the sociocultural norms that underpin them (Haney, 2018). In turn, social workers may rely on unquestioned socio-cultural norms and standardised practice approaches to fill the gaps in their understanding when engaging with neurodiverse service users (Haney \& Cullen, 2018). This is problematic, as it leaves room for ableist assumptions and biases to inform their practice (Krcek, 2013). Furthermore, as neoliberalism has continued 
to encroach upon social work service delivery contexts, it has established greater barriers to relationship-building and antioppressive practice (Morley, 2016).

The following article examines ways that social workers can resist, or reinforce, ableist practice norms that bolster the neoliberal status quo and foster oppression. This article presents insights from a qualitative research project that investigated ableism in relation to social work practice within neoliberal contexts. The research project sought to investigate the central question: how might normative approaches to interpersonal engagement reproduce oppressive social work practice? Normative approaches are defined in this research as the implicit rules of interpersonal engagement within certain socio-cultural fields of practice (Wiegmann, 2017). Oppressive practice is conceptualised as the attitudes and actions that reaffirm the power imbalances within social work relationships and perpetuate the marginalisation of de-valued social groups (Purcell, 2014).

\section{Background}

\section{The neurodiversity paradigm}

The medical model of disability focuses on discerning the difference between normal and abnormal human functioning (Masataka, 2017). Within this framework, cognitive impairments are conceptualised as deficits in the development of the brain associated with conditions like autism spectrum disorder (ASD), attention deficit hyperactivity disorder (ADHD), specific learning disorders, and intellectual disability (Armstrong, 2015). While the medical model has historically dominated the discourse around disability, this has been challenged in recent years by the social model of disability (SMD) which draws attention to the way that ability is socially and culturally constructed (Krcek, 2013). Proponents of this model argue that the way environments and social systems are structured determines people's ability to participate in society more than their impairment (McGee, 2012). Aligning with this model is the neurodiversity paradigm, which champions a pluralistic view of human ability that rejects normative constructions of functional and dysfunctional (Dinishak, 2016). A key feature of the neurodiversity paradigm is that people with cognitive differences are dis(abled) by socio-cultural structures that privilege these normative categorisations of functioning (Den-Houting, 2019).

\section{The link between ableism and social disadvantage}

Social, economic, and political environments are structured to reproduce normative constructions of functional ability (Leveto, 2018). By extension, functionalities that are considered atypical in relation to the normative standard are positioned as being innately defective, and are de-valued as a result (Masataka, 2017). These structures disenfranchise people who are cognitively diverse by establishing barriers to social mobility and community participation (McGee, 2012). For instance, normative expectations and discriminatory attitudes in the workplace foster an array of barriers for neurodiverse individuals when gaining and maintaining employment (Sarrett, 2017). In turn, neurodiverse populations are more likely to experience long-term unemployment, economic hardship, housing insecurity, and poverty (Bathje et al., 2018). Furthermore, neurodiverse populations have considerable incarceration rates, mostly in relation to petty crime or disorderly conduct when interacting with police (Ellem \& Richards, 2018). Moreover, people who are neurodiverse experience high rates of depression, anxiety, trauma, and substance abuse (Bathje et al., 2018).

\section{Limitations in current social work practice approaches}

Neurodiverse populations frequently access specialist disability services, however, these predominantly focus on the bio-psycho dimensions of wellbeing, discounting 
socio-economic factors (O'Connor, 2014). In connection to the social disadvantage that neurodiverse populations experience, they are over-represented as service users in health, welfare, and criminal justice systems (Ellem \& Richards, 2018). Services within these systems are generalist in nature, and, by design, often do not accommodate diverse support needs (Ellem et al., 2013). People who are neurodiverse communicate their thoughts and feelings in ways that deviate from normative concepts of being and doing (Masataka, 2017). This is often misinterpreted by social work practitioners who lack understanding of cognitive diversity (Haney \& Cullen, 2018), and consequently misjudge people's support needs (Haney, 2018). However, it can be argued that social workers currently have a limited scope of knowledge to draw from when expanding their understanding of neurodiversity and its implications for practice (Krcek, 2013).

\section{The need for critical social work research}

Medical research paradigms are scrutinised throughout critical disability literature for the way that they dehumanise people who are neurodiverse (Dinishak, 2016). Research examining the socio-political dimensions of ableism illustrates how the construction of difference as deficit reflects the structural disadvantage and interpersonal oppression that neurodiverse populations experience (Oliver, 2013). Social work research has used this socio-political framework to examine how paternalistic practice approaches are often underpinned by a tokenistic construction of (dis)abled identities (Hallahan, 2010). While social work research has embraced these critical frameworks, a significant portion of the existing literature about neurodiversity is grounded in medical paradigms that focus on deficit-based assessments and interventions (Krcek, 2013). Haney (2018) argues that social workers should employ the neurodiversity paradigm when expanding their understanding as it offers an anti-oppressive approach when engaging with existing knowledge around cognitive disability. Similarly, Muskat (2017) suggests that using a neurodiversity lens allows social workers to practise from a strengths-based approach when working within deficit-based contexts.

\section{Conceptual framework}

The research problem was conceptualised using Young's (2014) theory of oppression in conjunction with a social-political model of disability (Owens, 2015). A Bourdieusian theoretical lens was used to inform the analysis of doxas that reproduce the status quo of oppression within the social work field of practice (Edwards \& Imrie, 2003). Doxas were defined in this research as the absent but implicit rules of practice within each field, embodied in the performance of action (Oerther \& Oerther, 2018). The project also employs Bourdieu's notion of reflexivity, which embraces the way that socio-cultural discourse interconnects with the research practitioner's subjectivities as central to the knowledge-production process (Wiegmann, 2017). This research further draws on a poststructural approach, particularly Deleuzean theory, to critically question and re-value the meaning that is imposed by normative constructions of being and doing (Coleman \& Ringrose, 2013).

\section{Critical reflection as a research methodology}

Critical reflection focuses on examining the interconnection between power structures, social systems, and the narratives that we construct and infer meaning from (Morley, 2008). This is guided by the premise that subjective experience is a window into the social and political forces that manifest in the interpersonal aspects of practice (Daley, 2010). Central to this is the notion that the act of critically questioning our constructed meaning around phenomena can prompt us to reconceptualise the way that power works through our interpretation of truth (Fook \& Gardner, 2007). This draws from postmodern philosophical traditions, which propose that the meaning that we construct within 
a situation is not fixed, or universal across perspectives, but is instead multifarious and malleable to interpretation (Pease, 2009). Combining these insights with those from modernist notions of emancipation, critical reflection further examines how this meaning can be destabilised to foster one that is more transformative (Morley, 2014).

In this study I used Fook and Gardner's (2007) critical reflection model as a research tool to examine my construction of a social work field incident. This model was originally developed as an educational tool for social workers to use when evaluating their practice (Fook \& Gardner, 2007). Morley (2008) expanded on this by using critical reflection as a research methodology to analyse normative assumptions that underpin social work practice. I used a similar conceptual framework to inform the research methodology of this study. This involved recording my initial account of the incident as data for reflexive narrative analysis (see below). Deconstruction and reconstruction methods were then used to dissect, and subsequently re-write, the key narratives within my account of this incident (Morley, 2012). The present study examines how socio-cultural truths, that reinforce the status quo of power, influence the micro-political dimensions of social work practice. Therefore, this research used critical reflection as a counter-hegemonic approach to the medical paradigms that are predominant within existing understanding of neurodiversity (Dinishak, 2016).

The deconstructive analysis involved dissecting the assumptions that were underpinning my account (Fook \& Gardner, 2007). This located the socio-cultural narratives within my construction that had presupposed these assumptions as truth (Coleman \& Ringrose, 2013). Discourses were identified by examining the way that language was used throughout my account to construct these narratives (Foucault, 1974). Inspecting the unquestioned rules of practice in my construction revealed the underlying doxas that had informed my approach to the situation (Edwards \& Imrie, 2003). Moreover, this analysis investigated the portrayal of identity within my construction and the way that power had been fixed according to this (Morley, 2014). Central to this was asking critical questions such as: who benefits from my construction of power; and how would this construction change if the rules of practice were different? Additional insights and further avenues of reflection were generated by discussing my account of the incident during supervision sessions throughout my student placement.

The reconstruction process used a poststructuralist lens to destabilise and reconfigure the fixed notions of truth that were driving my initial construction of the incident (Morley, 2008). This approached meaning as multifarious, and therefore malleable, in order to re-value the significance that was attached to these notions (Coleman \& Ringrose, 2013). By reconstituting the dynamics of meaning within my initial construction, I was able to envision power as multi-faceted and open to subversion (Morley, 2014). Drawing these dynamics into the foreground allowed for the consideration of nuance, subjectivity, and multiplicity within my understanding of the situation (Fook \& Gardner, 2007). In challenging the dichotomous constructions that had established rigid boundaries of thought around the situation, I generated counter-hegemonic narratives as a way of resisting oppressive socio-cultural norms (Morley, 2012). This prompted me to contemplate alternative interpretations of my account that reframed the situation outside of the socio-cultural structures that were governing my construction of meaning (Bayliss, 2009).

\section{Ethical considerations}

This research did not require formal approval from a research ethics committee as I was the only active participant. Whilst the data collected was based on my construction of an incident, it portrays individuals who have not consented to their information 
being represented. The potential risk that this posed to confidentiality was mitigated by de-identifying my incident recording, i.e., organisational details have been excluded and a pseudonym has been used throughout to protect the anonymity of the individual featured. Furthermore, certain incident details have been omitted from the recording in order to further protect the anonymity of individuals featured within my account.

The purpose of this research was to enhance my critical reflexivity skills as an emerging social work practitioner. Maintaining and strengthening an anti-ableist framework was a core motivation in this endeavour. This is guided by a commitment to social justice and anti-oppressive practice, but also my experience of being autistic and struggling to interact with normative structures and neoliberal systems. My social work practice values are largely influenced by my own experience of communication barriers and needing others to advocate for me. The most troubling aspect of my critical incident was that I had engaged in the same oppressive practice that I have experienced first-hand from others. Therefore, it was crucial for me, both ethically and existentially, to critically interrogate the underlying assumptions that had informed my approach to practice in this incident.

\section{Summary of critical incident}

The following is an account of a practice incident that occurred during my final social work placement. This incident happened when I was supporting a service user, Aria, in going to her local welfare office. Aria had recently moved and needed to speak to the workers at the welfare office about updating her address details. Aria has a mild intellectual impairment and experiences difficulty with verbal comprehension and communication. She often masks this with acquiescence and by taking on a passive communication role. I was concerned that this may possibly cause Aria to misunderstand the workers' questions and to become confused.
I was also conscious of how inaccessible and punitive neoliberal welfare systems can be for vulnerable populations, so I asked Aria if she wanted me to speak to the workers for her. She agreed. In the end the workers changed Aria's address and did not question the information that I gave them. However, I feel that my approach to this interaction with Aria, particularly the way that I asked for permission to speak for her, was problematic. I did not take the time to discuss the situation with Aria or clarify why I was asking to speak on her behalf. I acted on the assumption that the system was too difficult for Aria to navigate without my assistance and therefore it was easier to speak to the workers for her without explaining why.

\section{Deconstruction}

A predominant assumption within my account of the incident was that Aria needed someone to speak on her behalf. Underlying this assumption was my belief that she was vulnerable to being overpowered by the welfare system because of the communication barriers inherent within its structure. This was underpinned by the notion that Aria's ability to communicate for herself was impaired and, therefore, would have struggled to navigate the interaction with the welfare officers. My construction was also directed by the assumption that the welfare system is too complex for Aria to understand, and so it would have been difficult for me to explain it to her. Interrogating these assumptions revealed how they reflect broader socio-cultural narratives about people with cognitive impairments lacking the functional capacity to comprehend the world around them, which create the communication barriers that they experience (Masataka, 2017). Deconstructing my account of the situation allowed me to identify the doxas that had presupposed these assumptions as fixed truths within my incident. For instance, operating within my construction was the doxa that verbal communication is the only way to transfer information (Phutela, 2015). 
This was established through a dichotomous construction of communication as either verbal or non-verbal.

The deconstruction process uncovered ableist discourses within my account that had reduced communication to a factor of verbal intelligence based on socio-cultural notions of the "functional" norm (Dinishak, 2016). This construction materialised power as verbal ability, which determined who could speak. For instance, throughout the incident Aria had the least power because I had discounted her ability to speak. Moreover, Aria's identity is defined by her impairment, which constructs her as vulnerable and incapable. I constructed myself as Aria's supporter/advocate based on a fixed identity of social workers as heroic shepherds for the vulnerable (Hyslop, 2018). In contrast, the welfare officers were constructed as being bureaucratic gatekeepers of justice who were obstructionist and punitive (Gwilym, 2018). Upon deeper inspection of this, it became apparent that, by defining identity in these terms, I had allocated myself the power to direct decision-making within the situation. Furthermore, my perception of this managerial barrier resulted in a paternalistic approach to practice that disempowered Aria by marginalising her right to selfdetermination (Wallace et al., 2011).

I identified two key oppositional assumptions in my account that were implicated in the construction of power:

1) myself versus the welfare officers; and

2) Aria versus the welfare system. These fixed dynamics of practice were established through an oppressor and supporter dichotomy, which simultaneously delegated power according to these roles (Singh \& Cowden, 2015). This fostered a hierarchical construction of power that positioned the welfare officers at the top and Aria at the bottom. Further analysis revealed the implicit doxa that service systems are designed to reproduce social disadvantage and need to be navigated on the basis that they are inaccessible for people with cognitive impairments (Garrett, 2010).
This was generated through a discourse of neoliberal fatalism, whereby the welfare system is constructed as being so managerial that it ultimately aims to obstruct rather than assist the people it was set up to support (Wallace et al., 2011). By extension, there is no space within this system for empathy or flexibility.

\section{Reconstruction}

When reconstructing my initial account of the incident with Aria, I needed to confront the narratives that had constructed her in (dis)ableing terms (Owens, 2015). Medical paradigms that pathologise neurodiversity are reflected in socio-cultural norms that devalue difference, which permeate throughout our collective unconscious and manifest in unquestioned assumptions and practices (Lollini, 2018). Post-structural theorists like Deleuze argued that there is no intrinsic value or purpose to human ontology (ways of being and doing), as nature is an everchanging pattern of difference (Bayliss, 2009). Instead, socio-cultural constructions of normative ascribe meaning to human activity and define what forms of functioning are valued within certain contexts (Coleman \& Ringrose, 2013). In order to destabilise the problematic construction of Aria, I used a lens of brain plurality to counteract the meaning that had been imposed through socio-cultural categorisations of impairment (Lollini, 2018). This allowed me to resist hegemonic constructions of cognitive deficit by embracing human neurodiversity as a vital part of the variation and difference that is fundamental throughout nature (Bayliss, 2009).

During the reconstruction process, I questioned why I had used verbal communication norms to define the parameters of engagement with Aria. These norms reflect structuralist notions that construct communication and interpersonal skills as innate psycho-linguistic traits that have universal meaning across human interactions (Chomsky \& Foucault, 2011). However, there are many forms of 
communication, as each person has a unique way of understanding the world based on their subjective experiences and individual cognitive differences (Ivanov \& Werner, 2010). I wondered how my construction of the situation would change if I considered the vast potential of communicative diversity as expanding, rather than limiting, the avenues of engagement with Aria (Phutela, 2015). In reframing my construction through this lens, I generated counter-narratives about how I could have diversified my approach to communication when engaging with Aria. For example, I wondered how the incorporation of visual and/or written communication tools within my approach could have assisted in explaining the situation to Aria.

Throughout my initial construction I conflated my role in advocating for Aria with the need to be adversarial towards the welfare workers. In deconstructing this, I realised that it was underpinned by ableist discourses that had informed a paternalistic approach to practice (Gwilym, 2018). In turn, my attempt to shield Aria from unjust systemic structures inadvertently minimised her agency and bolstered the status quo of power. Foucault (1974) describes how discourses reaffirm the power dynamics within a social field by governing our sense of agency as subjects in relation to them. This is exemplified in the way that I submitted to the predetermined rules of neoliberal welfare systems and subsequently discounted the possibility of practising outside them. Neoliberal ideology disenfranchises pluralistic ways of being and doing by reinforcing attitudes and practices that normalise historical injustice and structural oppression (Owens, 2015). I reproduced this process of oppression in my practice by using a normative approach to define the rules of engagement with Aria (Bayliss, 2009).

Interrogating my initial construction revealed how my approach to the situation with Aria was informed by a teleologicalconsequentialist ethical framework (May, 1980). For instance, the outcome of my practice (helping Aria avoid potential financial penalty) was the primary focus and therefore justified the means of achieving it (speaking on Aria's behalf). However, by constructing the situation in these terms, I had unwittingly allowed neoliberal doxas to define the purpose of my practice and working relationship with Aria. In order to shift this construction, I considered what might have occurred if I had removed myself from the situation entirely and left Aria to engage with the welfare system by herself. I realised that this would have potentially disempowered Aria even further by minimising her neurodiversity and disregarding her right to supported decisionmaking (Owens, 2015).

In reconstructing this, I wondered if it was possible to implement a framework of understanding around the situation that draws on a feminist ethics of care without abandoning my original analysis of power (Gray, 2010). Feminist ethical theories place emphasis on the relational aspects of social work practice by highlighting the importance of working alliances that empower vulnerable people (May, 1980). When applying this lens to my incident, it can be seen how forming a reciprocal and collaborative alliance with Aria should have been central to my role in supporting her. By constructing the situation in outcomebased terms, my approach to practice was guided by the perceived threat of neoliberal oppression and the consequences associated with this (Singh \& Cowden, 2015). Instead, I could had focused on working with Aria to navigate these barriers as a team. This would have involved positioning engagement as the primary "goal" of my practice by prioritising relationship-building as a key "outcome" (Gray, 2010).

\section{Discussion}

The findings from this critical analysis provide an insight into the interpersonal dimensions of oppression and ableism within the context of social work practice. Oppression, in all forms, involves marginalising certain groups of 
people by relegating them to a disadvantaged social position that limits their access to resources and opportunities (Young, 2014). Interpersonal oppression is not necessarily enforced by direct political authority, but instead through social and cultural norms that inform people's actions and attitudes towards de-valued identities (Purcell, 2014). This research presents a practice-based example of interpersonal oppression and the micro-political factors that underpin it. The analysis revealed that ableist assumptions about cognitive functioning contributed to a paternalistic approach when engaging with a neurodiverse service user. This aligns with the premise that interpersonal engagement is inherently micro-political as it reflects hegemonic socio-cultural norms (Dinishak, 2016).

A key theme within my analysis was the intersection between ableism and neoliberal welfare systems (Spies-Butcher \& Chester, 2014). Neoliberalism places emphasis on individual responsibility and self-sufficiency which, in turn, normalises structural oppression and social inequality (Mladenov, 2015). Consequently, neoliberal systems foster greater levels of oppression for structurally disadvantaged groups as they operate on the presumption that everyone has equal opportunity and universal access (Parker Harris et al., 2012). Furthermore, neoliberal ideology reinforces a commodified view of human functioning, whereby ableist discourse is positioned as common sense, i.e., people with disabilities are disadvantaged because they are dysfunctional and therefore "unable" to do (Mladenov, 2015). Following this logic, power is exercised through socio-cultural constructions of functioning that reaffirm the neoliberal status quo (Lollini, 2018). These research findings align with critical disability literature that has identified patterns of oppression and inequality across a broad scope of social structures (Oliver, 2013).

\section{Implications for social work practice}

The incident in this critical reflection took place at the beginning of my final social work placement. Therefore, the insights from this analysis had a profound impact on my learning while on placement, and have continued to shape my approach as an emerging practitioner. When this incident occurred, I was immediately aware that I had engaged in oppressive practice, but I could not envision any alternatives to it. I knew that I had made the right decision to speak on Aria's behalf; however, I was uncomfortable with my assumptions about her ability to understand and participate in this process. Using critical reflection to confront the aspects of my approach that were incongruent with my anti-oppressive practice values allowed me to examine the ethical tensions that were underpinning this incident (Morley, 2012). An important insight from this was that anti-oppressive practice is an on-going process, in the sense that it requires continuous learning and reflection.

One of the lasting implications that this critical reflection has had for my practice is a greater appreciation of how I can prioritise a flexible engagement approach, one that draws on diverse modes of communication, when working with people who are neurodiverse. A key finding from this research was that interpersonal engagement is a dynamic, and constantly evolving process of relationship building. My initial construction of the incident had placed emphasis on Aria's neurodiversity as an engagement barrier in our working relationship rather than considering how my own approach factored into this. In realising this, I started to focus on how I could have adapted my practice to Aria's individual communication style instead. These findings align with existing social work literature that identifies a person-centred approach as "best practice" in disability settings (Bigby, 2012). Central to this is forming collaborative relationships with people that support their participation in decision-making processes (Douglas \& Bigby, 2018).

This critical analysis provides insight into the micro-political dimensions of interpersonal engagement as they illustrate how ableist 
discourses had informed my construction of Aria's identity. Arguably, for person-centred practice to be legitimate, social workers must reflect on how they have constructed this person-hood and the socio-cultural narratives that may inform it (Krcek, 2013). This is particularly crucial when working within neoliberal structures that pressure social services to prioritise operational efficiency over relationship-building and personcentred care (Spies-Butcher \& Chester, 2014). These structures have made it increasingly difficult for social workers to engage in critically reflective praxis that recognises the dynamics of power and privilege within their practice (Morley, 2016). This was apparent in my incident as the neoliberal practice context had amplified the existing factors of oppression within my working relationship with Aria. However, by critically reflecting on this, I was able to challenge my assumptions around purposeful practice and diversify my construction of power.

Throughout this research, a neurodiversity lens was pivotal in shifting my construction of Aria's ability to participate in this situation. There is an emerging social work literature base around the anti-oppressive potential of implementing a neurodiversity paradigm to challenge deficit-based understandings of cognitive functioning (Krcek, 2013). The findings from this study exemplify this as they suggest that the application of a pluralistic framework may assist social workers when engaging with cognitively diverse service users (Muskat, 2017). These findings also provide insight around the importance of using critical reflection to challenge normative assumptions about cognitive functioning and interpersonal engagement. This interpretation invites social workers to see the engagement process as an opportunity for micro-political resistance to the normative structures that reproduce the socio-cultural status quo.

\section{Limitations}

The case study format of this research is a key limitation as the findings only capture a singular practice experience. Therefore, it is difficult to draw conclusions from this analysis that can be implemented across the broader context of social work practice. Nevertheless, this research provides new insights into how critical reflection can be used with social work practitioners to challenge the normative constructions that shape their understanding of neurodiversity. Future research into this topic would ideally collect incident data from multiple participants and investigate key themes across their accounts of different practice contexts.

\section{Conclusion}

In summary, this study investigated the interconnection between normative rationality and socio-political discourse through analysis of a critical practice incident. I used a process of critical reflection to analyse the normative assumptions within my account of this incident. This involved deconstructing the socio-cultural narratives that were underpinning my account in order to generate alternative interpretations of the situation that simultaneously reauthored these narratives (Morley, 2014). My initial construction of the incident was underpinned by modernist understandings of power and identity that had fostered a dichotomous approach to practice. This construction was challenged by examining the unquestioned assumptions that were underpinning my account of the situation and exploring diverse ways of thinking about power (Fook \& Gardner, 2007). Central to this was elucidating the discursive and ideological mechanisms of power, and how they had manifested, and were reproduced, within my construction.

A key factor within my construction of power was that I had allowed neoliberal doxas to define and constrain the parameters of my practice. This was echoed in the findings as my adversarial approach to the welfare system was engendered by a sense of neoliberal fatalism that ultimately bolstered the status quo of oppression 
(Garrett, 2010). Moreover, the construction of power in commodified terms had informed a consequentialist ethic within my approach, whereby the outcome of my practice had justified the means of achieving it (Gray, 2010). The analysis further revealed the ableist discourses within my account that had defined cognitive impairment in terms of innate deficit, which subsequently legitimised a paternalistic approach to practice (Mladenov, 2015). Destabilising this allowed me to implement a pluralistic framework of understanding of difference as diversity rather than deficit. In doing so, I expanded my understanding of interpersonal engagement by considering ways in which I could have prioritised a relational approach to practice and minimised the power imbalance between myself and the service user.

\section{Acknowledgements}

The author of this article wishes to acknowledge Christine Morley for academic inspiration and guidance, Sandiellen Black for providing essential learning support, and Sandra Cookland for additional feedback and support.

\section{Accepted 19 February 2021}

Published 25 April 2021

\section{References}

Armstrong, T. (2015). The myth of the normal brain: Embracing neurodiversity. AMA Journal of Ethics, 17(4), 348-352. doi:10.1001/journalofethics.2015.17.4.msoc1-1504

Bathje, M., Lannoye, M., Mercier, A., \& Panter, K. (2018). A review of occupation-based life skills interventions for adults with neurodevelopmental disorders. Occupational Therapy in Mental Health, 34(2), 165-180. doi:10.1080/0 164212X.2017.1360168.

Bayliss, P. (2009). Against interpretosis: Deleuze, disability, and difference. Journal of Literary \& Cultural Disability Studies, 3(3), 281-294,305. doi:10.1353/jlc.0.0023

Bigby, C. (2012). Social inclusion and people with intellectual disability and challenging behaviour: A systematic review. Journal of Intellectual and Developmental Disability, 37(4), 360-374. doi:10.3109/13668250.2012.721878

Burgers, C., \& Beukeboom, C. (2016). Stereotype transmission and maintenance through interpersonal communication: The irony bias. Communication Research, 43(3), 414-441. doi:10.1177/0093650214534975
Chomsky, N., \& Foucault, M. (2011). Human nature justice versus power: The Chomsky/Foucault debate. Souvenir Press.

Coleman, R., \& Ringrose, J. (2013). Deleuze and research methodologies. Edinburgh University Press.

Daley, A. (2010). Reflections on reflexivity and critical reflection as critical research practices. Affilia, 25(1), 68-82. doi:10.1177/0886109909354981

Den-Houting, J. (2019). Neurodiversity: An insider's perspective. Autism, 23(2), 271-273. doi:10.1177/1362361318820762

Dinishak, J. (2016). The deficit view and its critics. Disability Studies Quarterly, 36(4), 5. doi:10.18061/dsq. v36i4.5236.

Douglas, J., \& Bigby, C. (2018). Development of an evidence-based practice framework to guide decision making support for people with cognitive impairment due to acquired brain injury or intellectual disability. Disability and Rehabilitation, 1-8. doi:10.1080/09638288.2018.1 498546

Edwards, C., \& Imrie, R. (2003). Disability and bodies as bearers of value. Sociology, 37(2), 239-256. doi:10.1177 /0038038503037002002

Ellem, K., O'Connor, M., Wilson, J., \& Williams, S. (2013). Social work with marginalised people who have a mild or borderline intellectual disability: Practicing gentleness and encouraging hope. Australian Social Work, 66(1), 56-71. doi:10.1080/0312407X.2012.710244.

Ellem, K., \& Richards, K. (2018). Police contact with young people with cognitive disabilities: Perceptions of procedural (in)justice. Youth Justice, 18(3), 230-247. doi:10.1177/1473225418794357

Fook, J., \& Gardner, F. (2007). Practising critical reflection: A resource handbook. Open University Press.

Foucault, M. (1974). The order of things: An archaeology of the human sciences. Vintage Books.

Garrett, P. (2010). Examining the "Conservative Revolution": Neoliberalism and social work education. Social Work Education, 29(4), 340-355. doi:10.1080/02615470903009015

Gray, M. (2010). Moral sources and emergent ethical theories in social work. British Journal of Social Work, 40(6), 1794-1811. doi:10.1093/bjsw/bcp104

Gwilym, H. (2018). Social work, neoliberalism and authoritarianism: An analysis of the policy document "Regulating Social Workers." Critical and Radical Social Work, 6(3), 407-413. doi:10.1332/20498601 8X15388226259290

Hallahan, L. (2010). Legitimising social work disability policy practice: Pain or praxis? Australian Social Work, 63(1), 117-132. doi: 10.1080/03124070903515458

Haney, J. (2018). Reconceptualizing autism: An alternative paradigm for social work practice. Journal of Progressive Human Services, 29(1), 61-80. doi:10.1080/10428232. 2017.1394689

Haney, J., \& Cullen, J. (2018). An exploratory investigation of social workers' knowledge and attitudes about autism. Social Work in Mental Health, 16 (2), 201-222. doi:10.1080/15332985.2017.1373265

Hyslop, I. (2018). Neoliberalism and social work identity. European Journal of Social Work, 21(1), 20-31. doi:10.1 080/13691457.2016.1255927 
Ivanov, M., \& Werner, P. (2010). Behavioral communication: Individual differences in communication style. Personality and Individual Differences, 49(1), 19-23. doi:10.1016/j.paid.2010.02.033

Krcek, T. (2013). Deconstructing disability and neurodiversity: Controversial issues for autism and implications for social work. Journal of Progressive Human Services, 24(1), 4-22. doi:10.1080/10428232.2013.740406

Leveto, J. (2018). Toward a sociology of autism and neurodiversity. Sociology Compass, 12(12), 1-17. doi:10.1111/soc4.12636

Lollini, A. (2018). Brain equality: Legal implications of neurodiversity in a comparative perspective. New York University Journal of International Law and Politics, 51(1). http://nyujilp.org/wp-content/uploads/2019/01/ NYI102.pdf

Masataka, N. (2017). Implications of the idea of neurodiversity for understanding the origins of developmental disorders. Physics of Life Reviews, 20, 85-108. doi:10.1016/j.plrev.2016.11.002

May, W. (1980). Doing ethics: The bearing of ethical theories on fieldwork. Social Problems, 27(3), 358-370. doi: $10.2307 / 800254$

McGee, M. (2012). Neurodiversity. Contexts, 11(3), 12-13. doi:10.1177/1536504212456175

Mladenov, T. (2015). Neoliberalism, postsocialism, disability Disability \& Society, 30(3), 445-459. doi:10.1080/09687 599.2015 .1021758

Morley, C. (2008). Developing critical reflection as a research methodology. In P. Liamputtong \& J. Rumbold (Eds.), Knowing differently: An introduction to experiential and arts-based research methods (pp. 265-280). Nova Science.

Morley, C. (2012). How does critical reflection develop possibilities for emancipatory change? An example from an empirical research project. British Journal of Social Work, 42(8), 1513-1532. doi:10.1093/bjsw/ bcr153

Morley, C. (2014). Using critical reflection to research possibilities for change. British Journal of Social Work, 44(6), 1419-1435. doi:10.1093/bjsw/bct004

Morley, C. (2016). Promoting activism through critical social work education: The impact of global capitalism and neoliberalism on social work and social work education. Critical and Radical Social Work, 4(1), 39-57. doi:10.133 2/204986016X14519919041398

Muskat, B. (2017). Celebrating neurodiversity: An oftenoverlooked difference in group work. Social Work with Groups: Group Work Stories Celebrating Diversity, 4O(12), 81-84. doi:10.1080/01609513.2015.1067131

O'Connor, M. (2014). The National Disability Insurance Scheme and people with mild intellectual disability: Potential pitfalls for consideration. Research and Practice in Intellectual and Developmental Disabilities, 1(1), 17-23. doi: 10.1080/23297018.2014.908815

Oerther, S., \& Oerther, D. (2018). Pierre Bourdieu's theory of practice offers nurses a framework to uncover embodied knowledge of patients living with disabilities or illnesses: A discussion paper. Journal of Advanced Nursing, 74(4), 818-826. doi:10.1111/jan.13486

Oliver, M. (2013). The social model of disability: Thirty years on. Disability and Society, 28(7), 1024-1026. doi:10.108 $0 / 09687599.2013 .818773$
Owens, J. (2015). Exploring the critiques of the social model of disability: The transformative possibility of Arendt's notion of power. Sociology of Health \& IIIness, 37(3), 385-403. doi:10.1111/1467-9566.12199

Parker Harris, S., Owen, R., \& Gould, R. (2012). Parity of participation in liberal welfare states: Human rights, neoliberalism, disability and employment. Disability \& Society, 27(6), 823-836. doi:10.1080/09687599.2012. 679022

Pease, B. (2009). From evidence-based practice to critical knowledge in post-positivist social work. In J. Allan, L. Briskman, \& B. Pease (Eds.), Critical social work Theories and practices for a socially just world (2nd ed. pp. 45-67). Allen \& Unwin.

Phutela, D. (2015). The importance of non-verbal communication. IUP Journal of Soft Skills, 9(4), 43-49. http://search.proquest.com/docview/1759007009/

Purcell, E. (2014). Oppression's three new faces: Rethinking Iris Young's "Five Faces of Oppression" for disability theory. In S. Asumah \& M. Nagel (Eds.), Diversity, social justice, and inclusive excellence: Transdisciplinary and global perspectives (pp. 185-206). State University of New York Press.

Sarrett, J (2017). Interviews, disclosures, and misperceptions: Autistic adults' perspectives on employment related challenges. Disability Studies Quarterly, 37(2), 6. doi:10.18061/dsq.v37i2.5524

Singh, G., \& Cowden, S. (2015). The intensification of neoliberalism and the commodification of human need - A social work perspective. Critical and Radical Social Work, 3(3), 375-387. doi:10.1332/20498601 5X14417170590709

Spies-Butcher, B., \& Chester, L. (2014). Marketisation and the dual welfare state: Neoliberalism and inequality in Australia. The Economic and Labour Relations Review, 25(2), 185-201. doi:10.1177/1035304614530076

Wallace, J., Pease, B., Noble, C., \& Henrickson, M. (2011). Neoliberalism and Australian social work: Accommodation or resistance? Journal of Social Work, 11(2), 132-142. doi:10.1177/1468017310387318

Wiegmann, W. (2017). Habitus, symbolic violence, and reflexivity: Applying Bourdieu's theories to social work. Journal of Sociology and Social Welfare, 44(4), 95-116.

Young, I. (2014). Five faces of oppression. In S. Asumah \& M. Nagel (Eds.), Diversity, social justice, and inclusive excellence: Transdisciplinary and global perspectives (pp. 3-33). State University of New York Press. 